\title{
The Next Generation Information Infrastructure for International Trade
}

\author{
Stefan Henningsson ${ }^{1}$, Uri Gal ${ }^{2}$, Niels Bjørn-Andersen ${ }^{3}$, and Yao-Hua Tan ${ }^{4}$ \\ Copenhagen Business School, Center for Applied ICT, ${ }^{1}$ sh.caict@cbs.dk, ${ }^{3}$ nba.caict@cbs.dk \\ ${ }^{2}$ University of Sidney, Faculty of Economics \& Business, uri.gal@sydney.edu.au \\ ${ }^{4}$ Delft University of Technology, Dept. of Technology, Policy and Management and Vrije University of Amsterdam, \\ y.tan@tudelft.nl
}

Received 28 June 2010; received in revised form 12 November 2010; accepted 22 December 2010

\begin{abstract}
Regulators and actors in international trade are facing a difficult challenge of increasing control and security while at the same time lowering the administrative burden for traders. As a tentative response, the European Commission has introduced the concept of "trusted traders": certified traders that are in control of their business. Trusted traders are entitled to trade facilitations, faster border crossing, and fewer physical inspections. To enable the use of trusted traders, changes are required to the information infrastructure (II) of international trade. This article complements existing works on e-Government interoperability by a theoretically driven approach with theoretical development of the II concept and how II can be modified as additional focus. Following the principles of IS design research, this paper presents a design proposition for the II of international trade. Using theories of II development and change as kernel theory, our proposition presents a redesign of IT, organizational, human, and change and collaboration elements. The design proposition was evaluated and verified with proof of concept installations and a stakeholder value assessment. The paper contributes to the domain of II and how they may be changed to meet new requirements.
\end{abstract}

Keywords: Information infrastructure, International trade, Design research, E-customs, I3 model 


\section{Introduction}

International trade faces a difficult challenge. Concerns over terrorists using international shipments in their attacks, the spread of contagious diseases, and increased tax fraud has caused consumers and governmental agencies to demand enhanced control and traceability of products from producer to end consumer [51]. At the same time, growing global competition is forcing governmental authorities to reconsider the administrative burden put on trading companies to ensure competiveness of national actors. For example, the European Commission (EC) aims to lower the administrative burden for companies in the European Union (EU) by 25\% by 2012 [14]. These seemingly opposing pressures present a significant problem for actors involved in international trade.

The idea of a "trusted trader" is one approach currently being discussed in the EU to address these pressures [46], [52]. The trusted trader concept can potentially lower the administrative burden for traders and ensure a high level of control and security. It represents a paradigmatic shift in the relationship between governments and traders: instead of governments controlling businesses, companies accept responsibility for their traded goods and agree to demonstrate their control over processes upon request. If the trader is able to meet predefined requirements, it is granted a "trusted trader" status, which allows for trade simplifications and faster border-crossings. The status implies that governments will perform fewer physical inspections of the trader and accept periodical reporting of export and import data instead of specific details of each shipment, which gives the exporter greater flexibility and possibilities to rapidly respond to customer inquiries.

This paper reports on a joint project in which trade governors, traders, IT suppliers, and academic partners collaborated to redesign the information infrastructure (II) of international trade to meet the requirements of the trusted trader concept. The current process of international trade relies on an II that supports transaction based reporting and a fundamental distrust of traders, which run counter to the trusted trader concept. The technical infrastructure supporting traditional customs processes consists of silo systems limited to the specific business or governmental domain in which they are implemented [28]. When information is shared across organizational borders it is still mostly done by printouts on physical paper. A truck with export goods crossing the Russian-Finnish border may be required to present as much as 40 different paper documents to be granted passage [47]. However, to a large extent the information required for using trusted trader certification is already present in the domain-specific systems [27]. The Dutch beer exporter Heineken can be used as an example. It would be a disaster for Heineken if, when reaching the end customer, their products were contaminated, harmful or of low quality. Not the least, the quality aspect has led to Heineken developing computerized control and monitoring systems from farmer to end customer; that is, systems that monitor and keep track of how wheat and hop are grown, which raw materials end up in each batch, what bottles are filled from what batch, what bottles are included in a shipment, to which customer a shipment goes, which route the truck takes from warehouse to grocery store, and so on. These tightly interconnected systems and related control procedures enable Heineken to monitor the complete flow of products; these systems constitute an infrastructure that permits the trader to ensure that what reaches the end customer is of the quality the consumer expects and not harmful in any way. Should anything happen, Heineken is able to rapidly trace each bottle of beer through its complete process to the farm where the ingredients were produced.

Intuitively, the control Heineken in the example above has over their processing activities is in many ways a much stronger type of control than customs achieves through random checks at border crossings and paper-based reporting of export and import activities. In addition, since this IT-based control serves the internal quality concerns of the trader, the trader has an intrinsic motivation to continuously improve this monitoring capability. If governmental agencies get access to traders' monitoring capability and are given evidence by traders to assess the reliability of their IT monitoring capabilities, then traders can be considered by the government to be a trusted trader. For this to come true there is a need for a next generation infrastructure supporting international trade; an infrastructure where both the technical infrastructure and the social elements (concepts, processes) related to trade are interoperable, enabling paper-less data sharing across organizational borders.

The paper has two purposes. First, it proposes a design principle for reshaping the II of international trade to accommodate the trusted trader concept. Second, it aims to apply the knowledge gained by the work on the modification of the infrastructure to deepen our understanding of IIs and how they can be reshaped.

Drawing on Gal et al. [19] we conceptualise II as a system of standardised practices and modes of communication that emerge in relation to an interoperable technical infrastructure spanning across organisational boundaries. Using the terminology of IS design research, we build on the concept of II as kernel theory [23], [50], [58]. To our knowledge, the design science approach has not yet been applied to examine IIs. Previous works on II [23], [50], [58] were based on traditional case study methodologies where the researchers followed the development and evolution of infrastructures from an outsider's perspective. This has led to a basic understanding of what constitute IIs and how they function. Our research builds on this research and strengthens our understanding of how complex IIs can be designed and shaped.

This paper takes a complimentary view to many works on e-Government interoperability that are foremost practically oriented and concrete in their ambition, e.g. [34] - [35], [48] - [49]. With a starting point in the literature on IIs and how 
to reshape them, the paper is fundamentally theoretically driven. The approach to the II supporting international trade is conceptual, regarding the II of international trade as one instantiation of II. This approach puts primary emphasis on theoretical development in the problem area, still enabling practical advice for the investigated instantiation. Second we present the methodological approach of the study, which we frame as a design research study with II as kernel theory. Third we present our design proposition, and describe how it was developed and evaluated. Finally we relate our findings to the domain of II modification, draw conclusions from our findings, and discuss future steps required to validate our work.

\section{Information Infrastructure and E-government Interoperability}

The term infrastructure refers to any substructure or underlying system. It denotes the "basic physical and organizational structures (e.g. buildings, roads, power supplies) needed for the operation of a society or enterprise" (Oxford dictionary) without which contemporary organizations and societies cannot function. A common use of the term infrastructure is made both by researchers and practitioners in the field of information systems (IS). The concept of IT infrastructure is used to describe large and complex technological systems that support the functioning of entire organizations shared by a large number of people. Conventionally, the idea of II emphasizes the standardization of systems, data, and communication across the infrastructure [12]; standardized ways of operating are inscribed in technology, which links applications and people according to predefined notions of business processes, and requires the homogenization of practices across organizational units [13].

\subsection{E-government Infrastructures and Trade}

Over the past decades government organizations have embraced information technology (IT) to realize electronic service delivery to citizens and businesses and to increase their operational effectiveness. These initiatives are believed to enable "a longer-term transformation of government that goes far beyond online service delivery" [43] $p$. 164. Instead of merely digitalizing current government processes and activities, this transformation aims at leveraging the value of electronic government (e-government) initiatives [33]. It is a general belief that IS holds the capacity for strengthening efficiency, providing tools for security, and furthermore being an instrument for streamlining of e-government procedures (Irani et al., 2007; Lenk 2002). Reduction of their administrative tasks is welcomed by businesses which often consider their interaction with the public sector to be a burdensome task [17].

Along with the benefits that e-government service can offer lie a number of overarching challenges. These include the creation of inter-domain infrastructures that enable private and public parties to share information electronically: "[E-Government] Infrastructures are a kind of public and quasi-public utilities and facilities that are typically used by large numbers of different users. In daily life, people usually assume that the infrastructures exist and operate as expected. [...] An essential characteristic of infrastructures is that they are used by many different users, with the usage evolving over time, as may the type of users. Another characteristic is that the infrastructure offers value to the users only when a certain critical mass of users has been reached" [34] p. 233.

This paper is about the creation of an e-Government infrastructure for the specific purpose of enabling trusted traders. From a governmental perspective, a trusted trader is trustworthy if that trader can be trusted to carry out activities that normally only the government is authorized to do. It is not only about being certain that reported figures are accurate, but also about the desire to control external risks. It is a matter of internal controls, but just as much of softer issues such as integrity, corporate culture and morals.

The concept of being trusted" is that customs would rely on companies' self-internal control and work in a way based on mutual trust between the companies and the customs organization. The companies will be self-conscious about their own problems and risks, and instead of being audited in a traditional way they will enter an agreement with customs that companies themselves will inform customs about the problems and risks they may encounter.

To assess if an organization is trustworthy the customs organization needs to apply modern auditing techniques and approaches to facilitate this new concept. The auditing principle is systemic rather than transaction based controls. Customs will monitor the process by which the trader operates, not the outcome of the process as normal. There is thus a fundamental difference to most of the trust-models that are applied throughout the internet were trust is based on transaction history [1], [18]: you trust an e-Bay vendor based on 97\% satisfied customers - not based on you knowing exactly how the vendor operates internally. To have the latter insight, a computerized II where all processes leaves digital traces is fundamental.

\subsection{Constituents of a Supportive Information Infrastructure}

Technically, II is a set of heterogeneous, interoperable IT-systems that supports processes and actions [42]. The II perspective accentuate that it is a heterogeneous installed base, and not a homogenous system that supports many processes and actions [8]. It is important to stress that the different systems and components of the infrastructure are intricately interrelated; the IT base has sometimes been compared to an investment portfolio, which, however, is a rather simplistic metaphor. "Investment portfolios are usually very flexible and easy to change, manage, and control. 
[...] Infrastructures are different. The individual elements are very interdependent, and their size and complexity make them extremely difficult to control and manage" [22] p. 56. This, at least, is true for processes spanning over several independent organizations, such as international trade. The heterogeneity of IT components to support this processes invoke a need for interoperability tools to enable co-existence. The inherent complexity of IIs is additionally apparent in the process of their development. When it comes to Ils that span over several organisations, it is not only the social and organisational embeddedness that makes an information infrastructure difficult to manage, but the factor of a lacking common managerial level further adds to the complexity [29].

IT infrastructures are generally conceived of as large conglomerations of technological components and human skills that combine to serve the corporate needs of an organisation or an organizational network. This type of conceptualisation assumes that infrastructures can be distinguished from all that is not infrastructure, and that since infrastructures can be neatly identified, they can be managed in a fairly straightforward fashion [6], [24].

Although this view stresses the role of human IT infrastructure to the functioning of IT resources, human actors are conceptualised as mere technology users which follow certain rationalistic norms; their importance to the operation of IT infrastructure is assessed based on a predetermined set of skills which they may or may not possess. Furthermore, the human elements of the IT infrastructure are treated as separate from its technical elements: "the IT infrastructure concept can be divided into two related - but distinct components - a technical IT infrastructure and a human IT infrastructure" [9]. While separating the human elements from the technical elements of infrastructure may be conducive to creating an easily measureable analytical construct, it contributes to a narrow conceptualisation of the social processes that are involved in the shaping and functioning of IIs and to an oversimplification of their dynamics.

Several researchers have outlined an alternative understanding of infrastructures that more broadly acknowledges the interconnectivity of human and technical infrastructural elements. According to this perspective, IIs extend beyond mere materiality and predefined human skills to encompass social, organisational, and moral elements [5], [39]. Technically, the construction of an infrastructural system requires the establishment of protocols and standards that enable the system to be used and seamlessly connect with other systems. Socially, its construction necessitates the elaboration of a system of classifications that symbolically represent and organise things in society: people, classes, geographical areas, religions, civil status, and so on. As Edwards observes; "....although 'infrastructure' is often used as if it were synonymous with 'hardware'... all infrastructures... are in fact socio-technical in nature. Not only hardware but organisations, socially-communicated background knowledge, general acceptance and reliance, and near-ubiquitous accessibility are required for a system to be an infrastructure..." [15] pp. 187 - 188. We will therefore use the term II instead of IT infrastructure in the remainder of this paper.

IIs are highly complex socio-technical systems. They are "puzzles, or better collages, and so are the design and implementation process that lead to their construction and operation. They are embedded in larger, contextual puzzles and collages. Interdependence, intricacy, and interweaving of people, systems, and processes are the culture bed of infrastructure. Patching, alignment of heterogeneous actors, and bricolage (make do) are the most frequent approaches..." [12] pp. 2 - 3.

IIs are evasive phenomena which manifest themselves in ways that are less tangible and orderly than conventionally assumed. They encompass both technical and social elements and their boundaries cannot be easily outlined because of the complexity and dynamism of the components that constitute them. Star and Ruhleder [50] describe IIs as having the following characteristics: they are "sunk" into other structures, social arrangements, information practices, and technologies; they may extend beyond a single event or one-site practice; and they both shape and are shaped by the conventions of a community of practices.

The different sub-systems and components of the infrastructure are intricately interrelated and often span multiple organisational and institutional fields. Therefore they extend beyond the domain of any single managerial regime [29], which makes controlling them difficult. The complexity of IIs is additionally apparent in the process of their development, which typically involves multiple narratives and groups struggling to shape the standards and classification systems embedded in the infrastructure to reflect their values and interests.

Taking this idea into account brings to the fore a crucial point: working infrastructures involve the development of standardisation and classification systems. However, such standardisation stretches beyond technological artefacts, platforms, and protocols to include people's routines, communicative behaviours, and work practices [42]. Accordingly, drawing on Gal et al. [19] we conceptualise II as a system of standardised practices and modes of communication that emerge in relation to an interoperable technical infrastructure spanning across organisational boundaries. Such practices are acquired when actors are inducted into a community and undergo a process of socialisation whereby they internalise local knowledge, practices, language, and values. Over time, such artefacts and associated organisational arrangements and practices become taken for granted, at which point they recede into the background and become part of the infrastructure [50]. 


\subsection{Designing an Information Infrastructure for Enabling Trusted Traders}

IIs contain technological, human, and organisational elements. Technological elements consist of software and hardware components including data and communication protocols. Human elements refer to the skills and knowledge required to operate the II. Organisational elements are those processes and practices in which the infrastructure is embedded and through which it is enacted. Like technological elements, these may also be shared by multiple organisations.

That technological, human and organizational elements of II are intertwined and shared among many actors does not mean that they cannot evolve, or cannot be subject to purposive efforts. However, reshaping requires a holistic approach and implies inter-organisational changes and adjustments of work processes of multiple parties. Such an endeavour is not likely to be realised without appropriate collaboration models and change management approaches.

Consequently, conceptually redesigning an II to enable the use of the trusted trader concept entails redesign suggestions along technological, human, organisational, and collaborative dimensions. After the methodological section, these four dimensions will be used to present our design proposition of how to enable use of the trusted trader concept.

\section{Methodological Approach}

IS design science research is concerned with theory and knowledge for action; i.e. "how to do something" [20]. Van Aken [57] p. 22 argues that the core mission of a design science is "to develop valid knowledge that can be used by professionals in the field in question to design solutions to their field problems". With regard to the desired output of research we can in the IS field distinguish two principal types of IS design research. One type, being the dominant view, has a focus on the development of novel IT artifacts, e.g. [31], and IT artifact design theory, e.g. [56]. A more recent second type is based on the argument that it is not only novel IT artifacts and IT artifact design theory that IS design science research should develop. For example, Gregor and Jones [21] argue that IS design science research should not only concern prescriptions for designing technological products and applications, but also for designing methodologies and interventions. One of the most critical aims of IS design science research is to develop practical knowledge for the design and realization of different classes of IS initiatives, where IS are viewed as socio-technical systems and not just IT artifacts [11], [30]. Broadly speaking, IS design science research should be underpinned by a socio-technical view [4], [11].

The existing literature on II as accounted for in the last section suggest two alternative positions for the combination of II and IS design science. If subscribing to the view of technical and human elements of II being possible to fruitfully separate and address independently, then the traditional IT-artifact centered IS design science approach would be logical. This would entail development of technical interoperability tools such as standards, protocols, schemas, etc. However, without regard to how these artifacts should come into use. The development of the II supporting international trade involves supra-national bodies such as the United Nations (UN), World Trade Organization (WTO), World Customs Organization (WCO), EC, and in the EU alone 27 national customs organizations and more than two million traders. In a situation like this, it is more than a little naïve to think that the development of an interoperable technical infrastructure is not as much a political and social change process. Therefore, to align with our conceptualization of II and our understanding of how IIs such as the one supporting international trade evolve, we subscribe to the view that the scope of IS design science should extend beyond providing guidelines for developing IT artifacts [31], [41] to encompass their practical management, implementation and use. Accordingly, in addition to software and hardware artifacts we are also interested in "softer" aspects of IIs, such as organizational practices and collaboration models and how they are enacted and modified.

The objective of design research is to produce theory for guided action to achieve some expected outcome [20]. In this paper we use the concept of "design proposition" as formulated by Bunge [7] to frame our design theory. A design proposition is a heuristic rule with the following structure: "To achieve $Y$ in situation $X$, requires doing $Z$ ". In our case, $\mathrm{X}$ is the current II of international trade, $\mathrm{Y}$ is the ability to employ the concept of trusted traders, and $\mathrm{Z}$ is our proposed trusted trader II.

This study was carried out in the context of a large collaborative project, the ITAIDE project, with representatives from Danish and Dutch Customs, traders (Arla Foods, Heineken, United Paper Mill), IT providers (IBM, SAP, Resultmaker), and academic institutions (Copenhagen Business School, Free University of Amsterdam, University College of Dublin, and Münster University). Activities within the project were carried out in a collaborative manner with each of the partners providing their respective knowledge and skills. The research process followed the phases of the design research cycle outlined by Carlsson [10] who suggested that IS design research is an iterative process that includes a) problem identification, b) choice of an appropriate theory to approach the problem, c) development of prescriptive guidelines, d) testing, and e) reflection on test results. The last step then leads back to identification of new problems and restarts the process.

The ITAIDE project, initiated in January 2006 and terminated in 2010, was built around the concept of Living-Labs (LLs). LLs were defined as real world expirimental settings with established borders (see [37] for an elaborated 
discription of the LL concept). That is, instead of addressing all problems of II and international trade at the same time we used four LLs to address four delimited situations related to international trade. Our LLs focused on four specific products (Paper, Beer, Food, Drugs) that were centered around four different export organizations and represented four different export scenarios. The products were choosen since the all represent distinct issues related to trade: adminstrative hardship, export of excise goods, sensitivity of organic products, and counterfait issues. Each LL defined the major obstacles in the scenario and developed a redesign-suggestion in which the obstacles were addressed with solutions based in innovations in IT. Redesign solutions were instantiated in proof-of-concept implementations to prove consitency and feasability. This paper is not concened with the specific redesign solutions and developed IT artefacts per se. Rather this paper contains the synthesized analysis of all four LLs and focus on the conclusions for the II. For indepth descriptions of the work in the LLs see [45], [2], [25], and [32].

Given the collaborative and design oriented focus of the research, much of the research process took place in workshop-like settings where representatives from the participating parties were brought together. During the workshop, representatives discussed problems and opportunities with the current situation as well as drivers and barriers for redesigning the way international trade is carried out. All discussions were recorded and transcribed. In addition more formal interviews were carried out to confirm and clarify when needed.

The design process started by defining an initial problem: how to develop an II to support the trusted trader concept? The participants focused on the idea of trusted trader as a possible way to address the difficulties in the current systems of international trade and started to discuss the issues which would have to be addressed during the project. Certification of certain traders as more trustworthy is a common practice in customs control, but the trusted trader concept as such had not been previously used to design the trade II. Theories of IIs and how they are changed (Section 2) were used as fundamental kernel theory.

The design proposition was constructed gradually during a period of four years as problems with the current II unfolded. The project started in 2006 and went through four one-year phases, each phase corresponding to one of Carlsson's design cycles and terminating in an evaluation of a test installation. Each of the participating members addressed specific parts of the II where they held expertise. Minor iterations and feedback cycles were constantly taking place, but from an overall perspective the project went through four major iterative loops where parts of the design proposition were instantiated into tangible prototypes. These prototypes were tested using a value assessment framework. Testing was made with proof-of-concept installations in the LLs.

\section{Design Proposition: The Trusted Trader Information Infrastructure}

This section presents the trusted trader II as a design proposition to construct an II that enables the trusted trader concept. We first elaborate on idea of trusted traders and what it demands from the II of international trade. Then we present the design proposition by a bottom-up approach, first presenting the innovations and conclusions drawn on the technological, human, organisational, and change dimensions of the Ils and subsequently using the input to synthesize a conceptual model explaining how IT innovations eventually can facilitate international trade through the use of II perspective and the trusted trader concept.

\subsection{The Trusted Trader Concept}

For centuries authorities have pursued transaction based controls of international trade. In this system, every international transaction is reported to the authorities and declared at the border. The growing scale of international trade in an increasingly globalized world has led to a huge pressure on customs authorities as well as to a heavy administrative burden for exporting and importing companies. Estimates claim that exporters spend $2 \%$ of their turnover on export administration [26].

A call for increased control and security in international trade in combination with a pressure to reduce administrative costs for traders have put IT and IS onto agenda of European Customs organizations. The idea is that electronic sharing of information required for customs purposes, so called e-Customs, may be the panacea for this dilemma. Modern IT solutions theoretically has the potential to not only reduce the cost associated with each information transaction, but to enable a paradigmatic transition from transaction based controls to systemic controls and certification of reliable traders as trustworthy. Throughout Europe work has begun to transform customs control to the model used for VAT reporting. Instead of reporting and controlling every transaction, companies may be certified as trusted traders who may only report export and import transactions periodically. To become certified, companies have to prove that they are in control of their business and product flows. Many companies already meet several of the future demands due to other governmental regulations (e.g. in the food industry) and internal efficiency and quality standards. For a more elaborate description of the trusted trader concept see [37].

In the EU a first step towards trusted trader certification is the Authorized Economic Operator (AEO) certification [53]. However, in its current shape, the AEO status enables few trade facilitations and is not very popular among traders. To enable a full use of the trusted trader concept, its supporting II has to change radically. The proposed II addresses the increased complexity of the trade network model, where individual isolated solutions are insufficient for establishing end-to-end control over the whole network. An essential extension of the trusted trader-concept is 
the concept of Trusted Trader Networks. By definition, international trade processes spans across organizational boundaries. As a consequence it is not sufficient for a trader to only regard internal processes in order to ensure end-to-end control of traded products, from initial producer to end consumer. Instead networks of traders have to be interconnected in trusted trader networks that can ensure end-to-end control. In these networks standardised data/process models and interoperability are essential to connect the different IT innovations of each partner in a trade network. Information sharing between companies is essential for these companies to become an efficient and trusted network.

\subsection{Technological Elements}

Regarding IT hardware, the existing information infrastructure fulfils many, but not all, needs. The actors in the ecosystem of international trade are already communicating with each other electronically - mostly through the Internet. Thus, some parts of the physical hardware are in place for communication. Regarding inter- and intraorganisation systems, one of the customs organisations made an investigation into what they would ask for regarding the traders' own enterprise system in order to grant the status of trusted trader. Eight functions were described, ranging for sending simple statements to customs that some goods were under "self assessment" to a more complex backwards tracing functionality. When applying these functionality requirements on internal systems of the trader companies in the living labs, most of these control functions were already covered. For example, in the food industry, backwards traceability of products is already a requirement. Only minor adjustments would be needed to, for example, fetch reference numbers to identify goods.

However, the trusted trader concept requires that upon request, the traders are able to prove that shipments are under control and are not manipulated somewhere during the transportation. To enable this, further IT innovations are required. These IT innovations are in many cases already available in the pilot phase, but still have to be adapted for large scale use. Showing how it could be applied is the contribution of the LLs. For example, in the LL concerned with beer export one of the technology providers in the project developed a container security and monitoring device that electronically sealed containers. The device logged information about container opening, temperature, and position. By integration with a supply monitoring software, containers could be tracked and traced in real time.

The tracing software was part of a Service-Oriented Architecture (SOA) developed as part of the design proposition. The SOA was implemented as a system to which traders and control agencies (e.g., Tax \& Customs) had access. In particular, it enabled the government to access the data base of the traders. This had two main advantages. First, the quality of the trader's data was much better because it came direct from the trader's own intra-organisational systems. In other words, business data were re-used for government control purposes. This is called Piggy-Backing. Second, the traders no longer needed to submit data to numerous different control agencies, and hence it led to a considerable reduction of administrative burden for them. This is called the transformation from data-push to datapull. In the old situation of data-push, the trader had to send data in all kinds of different formats and via different software applications to the government; in the new situation of data-pull, the trader only has to make business data accessible to control agencies, and the SOA enables these agencies to collect from the trader the right data at the right time. Clearly, strict policies have to be implemented to ensure that the control agencies only collect trade data that is relevant for control purposes, but it was shown in the living labs that modern public key cryptography is suitable to implement these policies in an appropriate way. Thus, trust was built with the ability to show control upon request.

In the LL associated with food export another inter-organisational system, based on SOA, was built as a common European database hub for export declarations. It was based on the idea that all European actors should interact which each other via this hub, rather than via direct bilateral links. To interface with the hub-software a common data model was needed. Currently, a trader is required to provide different information depending on the European country from which it is exporting. End-to-end control of the flow of goods requires data to be exchanged between two traders, between traders and authorities, and between authorities. A prerequisite for these exchanges is that all actors employ a standardised data model where the data elements have a universal meaning. The proposed II contains a proposal for a harmonized data model in the form of a UN/CEFACT compliant export schema. This is another example of the type of IT innovation that is needed.

Finally, three aspects of communication were developed in the design proposition. To communicate, the symbols that were interchanged needed to be understood unambiguously by the ones communicating. However, it was noted during the project that such an understanding already existed to some extent. A substantial amount of work on data meaning had already been done by UN/CEFACT, ISO, and DG TAXUD (EC's directorate for taxation and customs matters) to specify the meaning of cross-border trade data. However, this data standardisation is far from complete, and the completion is indeed a challenging endeavour. This is another example of IT innovation that is still ongoing. Already in the work on the paper based standard preceding e-Customs standards, the Single Administrative Document, many of these issues emerged and had to be solved. For such fairly unambiguous data fields such as "product description", there are also appropriate guidelines on how to provide and interpret data. Less attention has been given to the different modes of communication that exist. Sometimes digital signature or encryption is employed, and sometimes not. Sometimes data is pushed (i.e., actively submitted to appropriate governmental agencies and stored in the governmental systems) to the government agencies, and sometimes it is pulled from the 
traders systems (i.e., when data are needed they are fetched from the traders system by the demanding governmental agency). The design proposition contained a specification of suitable signature, encryption, and data retrieval mechanisms.

\subsection{Organisational Elements}

In the EU there are more than 400 Customs offices and more than 2,000,000 exporting and importing organisations spread over 27 countries. Obviously, it is impossible to talk about a common organisational or national culture. Some countries, such as the Scandinavian countries and the Netherlands, have a long tradition of granting trade facilitations based on certification. For example, the Swedish Stairway-accreditation enables trade facilitations in steps for Swedish traders fulfilling predefined requirements [54]. The Compliance Partnership Customs and Trade (COMPACT) model developed by Swedish and Dutch Customs jointly presents a framework for certification of traders as being reliable [53]. Other countries lack this tradition; generally, even in Scandinavia and the Netherlands, the fundamental idea behind customs control is that traders are expected to violate regulation until proven otherwise. The trusted trader concept builds upon a completely different foundation: that trusted traders are complying with regulation until proven otherwise. This new approach must be anchored in the mindset of both customs and traders in order to enable our design proposition. Ultimately, this means changes in legislation. The current legislation, based on the European Customs Code, as being the formalized interpretation of norms of values associated with export control, echoes the distrust perception. However, changes are already taking place in the EU as a decision has been taken on a modernized customs code that permits certain types of trusted trader certification process, such as the AEO.

Introducing the trusted trader concept means moving some parts of the export declaration processes to become internal for exporters. Thus, the interface between traders and customs is altered. Instead of 'ping ponging' data between organisations, export processes involving trusted traders boxes certain steps of the process, only notifying customs where the self control starts and ends. As the information infrastructure is bundled with the processes that embed it, all suggested innovations have been connected to process models showing the current as well as future processes.

What was also noted during the research with the II was that very few of the potential benefits of being a trusted trader would materialize if the status of trusted trader was not recognised in the destination country of the export. In this case, the Customs of the destination country would not apply trade facilitation, but would do all the traditional inspections of the goods at the border and require that all cross-border data and documents (for non-carrier of various diseases, of origin, quality, etc.) were provided by the trader before the goods could enter the country. Thus, most facilitation gained at the exporting country's side would be lost on the importing side. Therefore, worldwide agreements between countries regarding the acceptance of trusted trader certificates are essential accompany for the success of an information infrastructure for Trusted Trader Networks.

\subsection{Human Elements}

A shift to control by certification means a need for new knowledge and skills. Thousands of customs officers will have to perform control differently, and millions of employees at traders have to perform export differently. Groups such as veterinary and health authorities that become essential in the certification process and IT consultants that assist companies in modifying their enterprise systems to match the requirements for trusted trader certification are also required to perform new tasks. As part of our design proposition we have, together with various national customs organisations, developed a checklist and tools to assess how a company's enterprise system matches customs requirements for trusted trader certification. The proposition also contains learning materials. This material can be communicated through trade organisations.

During our workshops the invited traders reported that the introduction of e-Customs thus far had not led to any relief in the administrative burden, for which they cited two main reasons. First, as companies increased their ability to keep control of their business, the customs organisation continuously raised the bar for what should be reported and analyzed by the customs organisation. Electronic submission instead of paper based submission of data made analysis of large chunks of data possible, and necessary. Second, the authorities existed in silos and did not align their IT initiatives. The legal framework for IT-innovation in Europe, the Modernized Customs Code, was also identified as a barrier for adoption of the possible IT-innovation. As much control as possible, the silo-identification is a norm that has to be changed in order for the design proposition to be successful. The existence of the project in which this research was carried out is one of the measures taken to change these norms and values, by "neutral" researchers voicing issues and problems in the existing setup.

\subsection{Change and Collaboration Elements}

The change and collaboration elements of the proposed redesign can be divided into three parts: ecosystem mapping, collaboration model, and migration paths. An ecosystem analysis of international trade reveals that the trade is dependent on the collaboration of many organisations. Commercial businesses are linked in international supply chain that range, for example, from the individual farmer via purchasers, food processors, shippers, importers, 
and retailers to the end consumers. The actors in the supply chains are monitored by a large set of government agencies, such as national authorities for customs, tax, VAT, health, and statistics. Apart from traders and government agencies, the ecosystem also includes interest organisations for the various actors (e.g., SITPRO for British and EVO for Dutch shippers), and international collaboration and development organisations such as World Customs Organisation, WTO and UN/CEFACT. Lastly, providers of IT technology and services also take part in the ecosystem of international trade. The ecosystem analysis was included in the proposed redesign to highlight which actors needed to be included in any work to redesign the information infrastructure of international trade.

In order to bring all the above mentioned actors into the change process, a network collaboration model was developed as part of the redesign proposal. The model was developed upon the Network Management Framework (NMF) [44], representing aspects of the settings, and capturing their dynamic and precariously socialised existence. The conceptualisation of the environment as a network and its representation as the NMF is designed to emphasise the importance of governance structures for coordinating exchanges among network members.

Migration paths were also part of the change elements. For example, a non-submission vision was expressed, meaning that trusted traders should not submit any export data at all to customs in relation to their shipments. Data should only be pulled by customs from the exporter's internal systems upon request. However, the current legislation in many European countries does not support this pull mechanism. Instead, interim scenarios with a minimum data submission were developed as migration paths.

\subsection{The Integrated I3 Model}

This far in the paper, the constituent parts of an II supporting the next generation II of international trade has been presented. This section integrates the innovations and conclusion of the four dimensions into a conceptual model explaining how IT innovations eventually can facilitate international trade through the use of II perspective and the trusted trader concept. We name the model the ITAIDE Information Infrastructure (I3) Model (Figure 1).

The ultimate objective for the actors of international trade is to reduce the administrative burden at the same time as security and control in trade is improved. As depicted in Figure 1, this paper has explained that this could theoretically be achieved through the establishment of trusted traders and trusted trade networks. Trusted trade networks are networks of supply chains or interconnected trusted traders. A trusted trader is a trader that can be trusted to have full control of internal operations and thus is compliant with international and national legislation. Trusted trade networks enable accelerated trade since governments grant them the benefits of trade simplifications and reduced administrative burden. For more information on what makes up the trusted trader concept see [40], [45].

To be trusted, the trader has to prove to the government that the ability to do End-to-End Control and End-to-End Information Transparency of the goods in his supply chains. End-to-end control of shipments means control over operations and shipments from initial producer to end customer. However, having this control is not enough for being considered trustworthy. A trusted trader has also to be able to show to the government the control of its exports. End-to-end information transparency means that concerned control authorities can, at any given time, have complete access to relevant information about a specific shipment, for example, its physical location and who has access to the shipment. It is important to stress here that it is not a question about granting government unlimited access to all business data of a company. Developments in IT security have made it possible to grant access to those data that have been agreed upon between the government and traders as being relevant for government control purposes. End-to-End Control and End-to-End Information Transparency are in further detail described in [40].

The view on technical infrastructure comprised in this model is the infrastructure as a platform for control of shipments and information transparency in international supply chains. The infrastructure enables capabilities that are fulfilling the control requirements for being a trusted trader. Real-time monitoring is the capability to monitor and log real time - where a shipment is and how it is handled. Process control is the capability to document and evaluate that business processes meet control standards. Information sharing means the ability to electronically exchange information regarding shipments with trading partners and authorities. Partner collaboration refers to the joint capability of trading partners and IT providers to develop end-to-end control and transparency. These capabilities enable control, but are, in their turn, dependent on a set of IT-related innovations.

The IT-related innovations that enable capabilities of real time monitoring and transparency are IT artefacts such as smart seals that are mounted on containers and constantly report position, movements, temperature, and exposure to light. These innovations are doubtlessly essential for improving the traders control over its processes. For any trader, the ability to at any time provide governmental agencies with a detailed history of each shipment based on information reported from the digital seal will improve the trader's trustworthiness. However, the lesson learned in our four LLs is that the technical IT component is only one of the challenges of establishing an II that enables end-to-end control and information transparency. More about information about IT innovations see [3], for Standardised data models see [16], for Interoperability tools see [55], for Procedure redesign methods see [40], and for Network collaboration models see [38].

A concrete example of II development in the European trade area is the ongoing process of enabling so called Centralized Clearance (CC) of import and export goods. Many of Europe's two million traders are active in several of 
the EU's 27 member states. Each of the member states has its own trade legislation, declaration processes and inter-organisational systems, which the trader has to comply with for submitting electronic import and export declarations. For a pan-European trader, having to deal with as many as 27 different customs organisations, in different ways and using different IT systems, is complex and expensive. Large international companies, typically, have dozens of different inter-organisational systems to be able to do the electronic customs declarations in all the EU member states. With CC the ambition is that the trader should be able to submit import and export declarations to the customs organisation of the member state where the company's head office is located, regardless of to (and from) which EU country its goods are actually shipped.

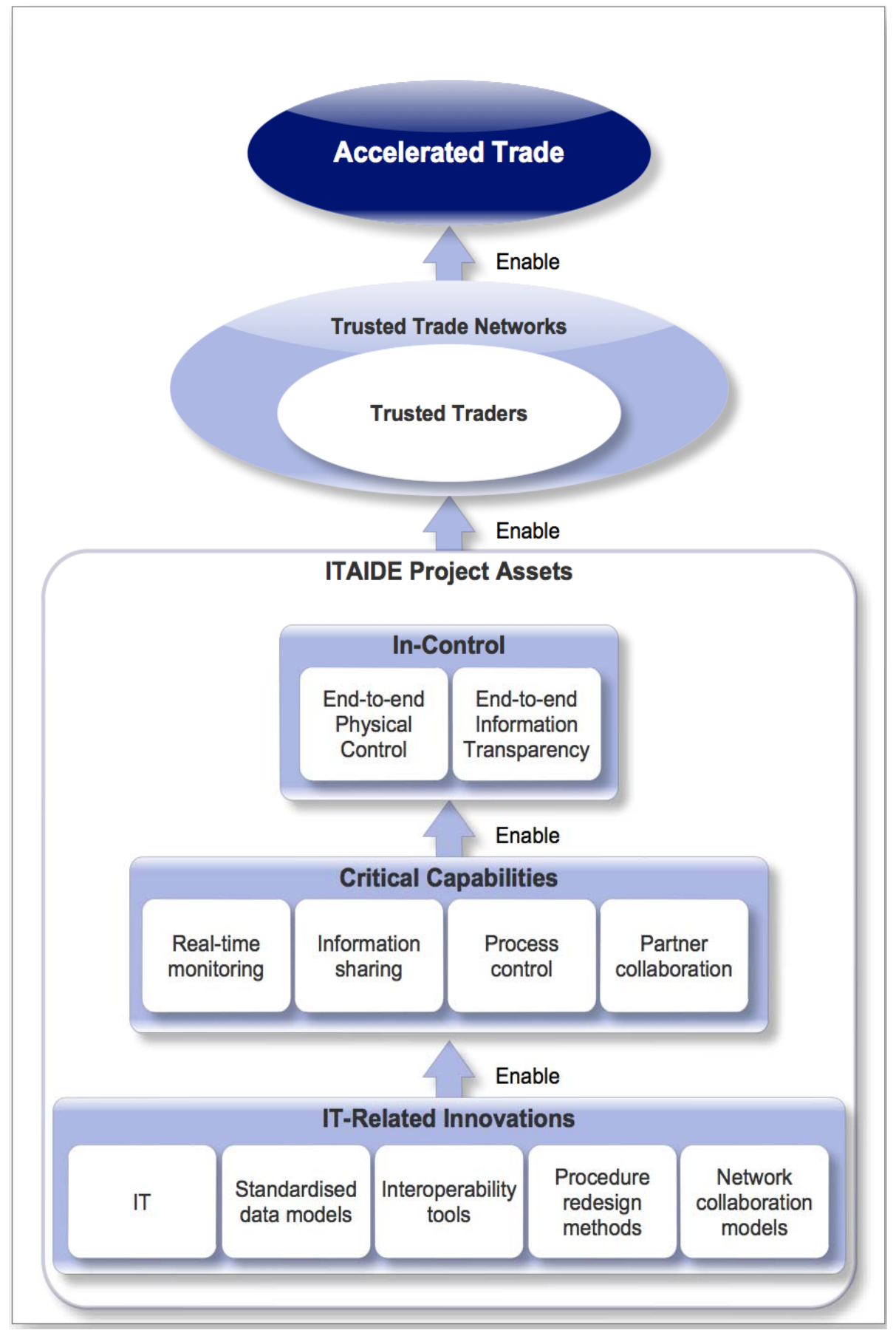

Figure 1: The 13 model

As with the development of any large-scale II, enabling CC presents major technical challenges. The 27 customs organisations have to set up EU-wide inter-organisational information systems between their own information systems to share export declarations. This exchange of trade data among national customs systems is only possible if the data elements to be submitted in an export declaration are standardised. Clearly, such a cross-border data 
model should not only be a standard within Europe, but also be aligned with international standards for cross-border data models that are currently developed by, for example, UN/CEFACT and WCO. Furthermore, technology and standards for encryption and digital signature also have to be implemented, and so on.

The technical development is a complex task, and the embeddedness in organisational and human components of the II is even more complicated. For example, the national data models represent the national view of risk assessment. Export declarations contain data elements regarding potential security risks, such as diseases, potential fraud, and other threats that are automatically assessed for need of inspection. A common data model requires international harmonization of risk assessments. To get 27 countries to agree on what are potential risks and how they should be assessed are problems that extend far beyond the technical challenges. The problems relate to fundamental norms defining the need for risk assessment, the organisational practices associated with it, and the legal context in which practices and norms are formalized in a specific country. Further, the export declarations reflect organisational practices. In some countries the customs officers can take the bike down to the main harbour to physically inspect goods, if necessary. In other countries inspections have to be planned 24 hours ahead due to the dispersed locations of customs offices and border crossings. In the end, the technical challenges of establishing the information infrastructure required for centralized clearance are eclipsed by these human and organisational issues.

The example above of an infrastructure enabling CC is a typical example in international trade that shows that there are several reasons for an II connecting traders and customs organisations in all 27 member states. The IT innovation for CC can also help companies to improve the control of their business processes, and hence become a trusted trader for the government. For example, the IT innovation for CC can be used by a company to get better control over its VAT administration. For two reasons, companies sometimes unintentionally underreport their VAT payments in a specific EU country: 1) they simply cannot trace whether their goods are travelling through this country or not, and 2) the logistics service provider decides about the optimal route for the goods, but this data is typically not shared with the trader. The IT innovation for CC could help companies to know exactly where their goods enter or leave a country, and hence to improve their VAT reporting to the government of this country. In this way, the company becomes better in control of its tax reporting duties, and this helps a company to qualify as a trusted trader for governments. In the following sections we provide more detail about how the existing information infrastructure may be reshaped to benefit trusted traders and eventually accelerated trade.

\section{Evaluation and Integration of Findings}

The design proposition outlines a model for realization of the trusted trader concept through the use of infrastructure for monitoring, control and sharing of information. This section reflects on the findings made in our research to draw general conclusions that increase our general understanding of large scale II and how they might be reshaped towards specific ends.

\subsection{Integrating Findings}

In the theoretical section we presented two alternative views of IIs. According to one view IIs are conglomerates of technological and human components. The second view regarded IIs as embedded into norms, values, and practices which to co-evolve with the technology to enable the functionality of the infrastructure. Our work aligns with the second view as it indicates that IIs cannot be easily isolated and managed as conglomerates of IT components. One of the most challenging steps in the design of the trusted trader infrastructure involved convincing the parties to initiate organisational changes. Many customs authorities are highly rigid institutions; they have traditionally avoided taking risks and initiating organisational changes or changes in their work practices. Furthermore, the current customs system is essentially functional. Therefore the infrastructural change was not backed by a real sense of urgency. Thus, a significant part of the infrastructural change process involved organisational rather than technological issues.

During a four year long process, and based on the limited existing research on the redesign of IIs, we identified many issues that needed to be addressed in order to create the trusted trader II. These encompassed collaborative, technological, human, and organisational elements and included the following: developing a standardised data model, implementing changes in international treaties, designing a process for submitting encrypted data, and initiating changes in national legislation (Figure 2). In Section 4 we detailed the specific design proposition for an II to enable the use of the trusted trader concept. Figure 2 presents how the experiences of developing this specific infrastructure can be abstracted to a general proposition of what is required to redesign a global II. 


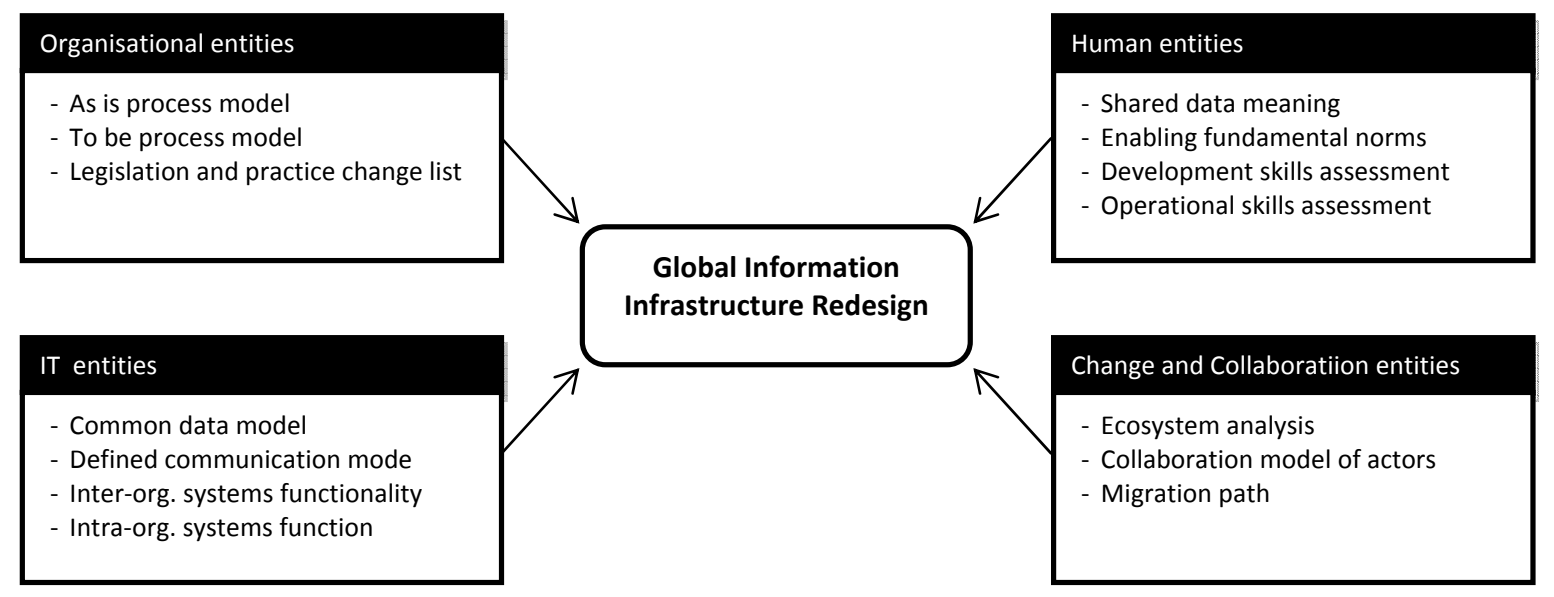

Figure 2: Global information infrastructure redesign

\subsection{Evaluation and Validation}

As mentioned earlier, this research took place in four iterations. Each iteration was associated with a LL. The labs were test beds for potential redesign propositions. Solutions to specific problems regarding international trade were implemented and validated as proof of concept-implementations. The implementations ran with actual transaction data from the traders and trade governors' systems. Representatives from traders and trade governors were part of the evaluation and interviewed afterwards.

Traditional value assessment, especially in the private sector, focuses on financial and productivity issues. The value of the 13 model could not be evaluated by purely financial measures. Rather, increasing the security and control in the supply chain and therefore being compliant to changing legal requirements in the future is also beneficial for participating stakeholders. Each of the four living labs was evaluated through a predefined value assessment framework based on academic research and best practices, see [36]. Assessing the value for governmental actors was not straightforward in that value cannot be measured only in economic terms. Eventually three goal areas were selected as desirable value additions for the design proposition: security, reduction of administrative burden, and reduction of fraud. The ability to add to these areas was addressed on four levels: financial, social, operational, and strategic.

A comprehensive description of the evaluation can be found in [36]. Generally the evaluation has been positive with substantial value found in all three value categories. However, the evaluation is made on test and proof-of-concept installation and further real world use is necessary to draw final conclusions. The project is currently working on putting the design proposition into real-life use. Not at least the collaboration models and migration paths have been found essential here as the shift into an II based on trusted traders is a paradigmatic shift that has to be accepted in all of the EU's 27 member states.

\subsection{Study Limitations}

The most significant limitation in this study is that testing of the proposed II as a whole was not feasible, due to the scale and flexibility. Currently the discussions in the EU and its member countries talks about having something similar (or alternative solution with similar functionality) in place by 2020 . Full scale implementation will imply legislative changes and IT changes in 27 member countries and at EU level. Therefore the proposed approach was tested piece-by-piece in proof-of-concept implementations in the living labs. It shall be recognized that the interlinked nature and complexity of II will lead to unforeseen events, effects and consequences as the full II eventually is being crafted. However, our approach could serve as a conceptual blueprint that identifies major components and enables discussion of how the components will influence each other.

\section{Conclusions and Future Research}

The paper introduced a design proposition to redesign the II of international trade to enable the trusted trader concept. The trusted trader II addresses the increased complexity of the trade network model, where individual and isolated solutions are insufficient for establishing end-to-end control over the whole network. For example, standardised data/process models and interoperability are essential to connect the different IT innovations of each partner in a trade network. Information sharing between institutions is essential for these institutions to become an efficient and trusted network. 


\subsection{Theoretical Contribution}

To redesign the II of international trade, organisational, human, and technological elements of the infrastructure need to co-evolve. The mutual dependencies between the different elements cannot be over-emphasized. A change in e-Customs systems must be matched with corresponding changes in the way the exporter declares export goods. Given that there are two million traders in Europe such an effort is complex and costly. Further, depending on the type of change, modification in legislation may also be required as well as modifications to norms and value systems of trade governors. Therefore an elaborated change approach is a fundamental constituent of the new infrastructure. Beside the contribution in the form of a design proposition for international trade, this paper also contains theoretical contribution to the field of II. Our conclusions regarding the redesign of a global II are summarised in Figure 2 . Four categories of measures are required, addressing organisation, human, technological and collaborative. In Figure 2 we outline the contents of the categories, but whereas the broader categories are general enough to last the test of time, the content needs further validation.

\subsection{Practical Contribution}

Putting a new II for international trade into practice is neither a straightforward nor unproblematic process. While the 13 model illustrates how IT-related innovations enable accelerated trade, it does not clarify how the innovations should be implemented, nor does it indicate the benefits that the stakeholders could expect to see along the way. Implementation, either individually or collectively, supports stakeholder organisations in moving from their current state of business to the future e-Customs domain. The evolution towards a next generation II supporting international trade can be described as evolution along two dimensions: trader interconnectiveness and technical sophistication. The first represents a move from individual organization to trader networks. The latter represents a maturity in the interoperability tools enable information sharing; standardisation, connectivity, and integration. By moving along these two dimensions it may be possible to eventually arrive at a fully interoperable II supporting the trusted trader concept and accelerated trade. However, barriers to overcome are not lacking. Barriers to overcome during the standardisation wave includes the total cost of IT investments, but perhaps more significantly there is the inequitable distribution of cost vs. return on investments across partners of varying sizes (i.e., large companies benefit more from standardisation activities than do SMEs). The investment cost will be a threshold, especially for SMEs. Barriers also include complexity of digitising existing data and the challenge to gain support from major influencers, especially across multiple national and international government organisations.

As the most tangible benefits are not realized until the actors of international trade has been through standardization, connectivity, and integration as well as formed trade networks, it is a significant challenge to ensure that the intermediate steps are successfully completed despite significant tangible benefits. Leading commercial trade organizations often choose ad hoc quick-fixes instead of long term viable solutions. However, once the integration is completed, implementation of the trusted trader concept is feasible due to end-to-end control over physical shipments across the entire trade chain and end-to-end information transparency across the entire trade chain. This will lead to safer and more secure supply chains with increased fiscal revenues and reduced fraud levels. The potential total cost savings in the order-delivery-invoice chain is high through the reduced administrative burden of cross border trade by reducing process complexity, and eliminating redundancy, reduced transaction costs, and internal efficiencies across the complete trade chains.

The suggested redesign approach contributes to the idea of eliminating paper documents in the customs process. The amount of paper documents in customs is still extensive. Reasons for a move towards electronic data flows are several. Besides environmental and resource utilization reasons, the costs of paper documents in the supply chain is substantial. A recent report from SITPRO on the cost of paper documents in the supply chain of perishable foods of the UK revealed that the supply chain produces approximately 1 billion papers annually of which $90 \%$ are destroyed. Consequences of UK's paper based supply chain is that duplicated data is key in at least 189 million times every year and 13 million man hours are spent on keying in data. All in all, the cost of papers in UK's supply chain of perishable food is estimated to $£ 1$ billion annually. It should be noted that this sum is only for perishable food and only for the UK. The sum for all supply chains in the EU is ungraspable. In the SITPRO report, however, a complete move to electronic information exchange is expected to reduce this cost by $70 \%$.

Finally, designing global II is becoming an important concern for IS research as globalisation and interconnectivity of the world is steadily increasing. Previous research has shown that corporate Ils are hard enough to redesign, but when it comes to global IIs, not only the increased scale but also the lack of a common management regime compounds the complexity. Nevertheless, global Ils are already adding substantial value to industries such as aviation and food and have the potential to make contribution to global trade.

\section{Acknowledgments}

This research is part of the integrated project ITAIDE (Nr.027829) funded by the 6th Framework IST Programme of the European Commission (see www.itaide.org). The ideas and opinions expressed by the authors do not necessarily reflect the views/insights/interests of all ITAIDE partners. 


\section{References}

[1] R. Alnemr, S. Koenig, T. Eymann, and C. Meinel, Enabling Usage Control through Reputation Objects: A Discussion on e-Commerce and the Internet of Services Environments, Journal of Theoretical and Applied Electronic Commerce Research, vol. 5, no. 2, pp. 59-76, 2010.

[2] J. Autere, K. Korpela, and K. Augustinussen, Paper Living Lab-Integration of SMEs, in Accelerating Global Supply Chains with IT-Innovation, Berlin: Springer Verlag, 2010, pp. 55-71, 2010.

[3] Z. Baida, F. Koldijk, Y. H. Tan, and A. Higgins, Information Technology (IT), in Accelerating Global Supply Chains with IT-Innovation, Berlin: Springer Verlag, 2010.

[4] R. L. Baskerville, J. Pries-Heje, and J. Venable, Soft Design Science Research: Extending the Boundaries of Evaluation in Design Science Research, in Second International Conference on Design Science Research in Information Systems and Technology, Pasadena, CA, 2007.

[5] N. Bjorn-Andersen, The human side of information processing, Amsterdam: North-Holland, 1980.

[6] M. Broadbent and P. Weill, Management by maxim: How business and IT managers can create IT infrastructures, Sloan Management Review, vol. 38, no. 3, pp. 77-92, 1997.

[7] M. Bunge, Scientific research ii: The search for truth. Berlin: Springer Verlag, 1967.

[8] B. Bygstad, Information Infrastructures as Organization, A Critical Realist View, in 29th International Conference of Information Systems (ICIS) Paris, France, 2008.

[9] T. A. Byrd and D. Turner, Measuring the flexibility of information technology infrastructure: Exploratory analysis of a construct, Journal of Management Information Systems, vol. 17, no. 1, pp. 167-208, 2000.

[10] S. A. Carlsson, Developing knowledge through IS design science research: For whom, what type of knowledge, and how, Scandinavian Journal of Information Systems, vol. 19, no. 2, pp. 75-85, 2008.

[11] S. A. Carlsson, Design science research in information systems: A critical realist approach, in Design science research in information systems: Theory \& practice, Eds.: Springer, vol. 22, pp. 209-234, 2010.

[12] C. Ciborra, From control to drift. Oxford, UK: Oxford University Press, 2000.

[13] C. Ciborra, The Labyrinths of Information: Challenging the Wisdom of Systems, Oxford, UK: Oxford University Press, 2002.

[14] EC, Measuring administrative costs and reducing administrative burdens in the European Union - COM(2006) 691, Commission of the European Communities, Brussels, 2006.

[15] P. M. Edwards, Infrastructure and modernity: Force, time, and social organization in the history of sociotechnical systems, in Modernity and Technolog. Cambridge, MA: M IT Press, 2003.

[16] B. Fluegge, A. Schmidt, M. Raus, and T. Vogel, Standardised Data Models, in Accelerating Global Supply Chains with IT-Innovation. Berlin: Springer, 2010.

[17] J. E. Fountain and C. A. Osorio-Urzua, Public sector: Early stage of a deep transformation, in The economic payoff of the internet revolution, Brookings Institution Press, Washington, DC, pp. 235-268, 2001.

[18] N. Gal-Oz, T. Grinshpoun, and E. Gudes, Sharing Reputation Across Virtual Communities, Journal of Theoretical and Applied Electronic Commerce Research, vol. 5, no. 2, pp. 1-25, 2010.

[19] U. Gal, K. Lyytinen, and Y. Youngjin, The Dynamics of IT Boundary Objects, Information Infrastructures, and Organisational Identities: The Introduction of 3D Modelling Technologies into the Architecture, Engineering, and Construction Industry, European Journal of Information Systems, vol. 17, no. 3, pp. 290-304, 2008.

[20] S. Gregor, The nature of theory in information systems, MIS Quarterly, vol. 30, no. 3, pp. 611-642, September 2006.

[21] S. Gregor and D. Jones, The Anatomy of a Design Theory, Journal of the Association for Information Systems, vol. 8, no. 5, pp. 325-335, 2007.

[22] O. Hanseth, The Economics of Standards, in From Control to Drift, The Dynamics of Corporate Information Infrastructures. Ed. Oxford: Oxford University Press, 2000.

[23] O. Hanseth and K. Braa, Hunting for the treasure at the end of the rainbow: Standardizing corporate IT infrastructure, Computer Supported Cooperative Work, vol. 10, no. 3-4, pp. 261-292, 2001.

[24] J. Henderson and N. Venkatraman, Strategic Alignment: Leveraging Information Technology for Transforming Organizations, IBM Systems Journal, vol. 38, no. 2/3, pp. 472-484, 1999.

[25] S. Henningsson, N. Bjorn-Andersen, A. Schmidt, B. Fluegge, and H. Zinner Henriksen, Food Living Lab Complexity of Export Trade, in Accelerating Global Supply Chains with IT-Innovation. Berlin: Springer, 2010, pp. 3-29.

[26] S. Henningsson and N. Bjørn-Andersen, When standards is not enough to secure interoperability and competitiveness for European exporters, presented at the 17th European Conference on Information Systems Verona, June 2009.

[27] S. Henningsson, R. Budel, U. Gal, and Y. H. Tan, The ITAIDE Information Infrastructure (I3) Model, in Accelerating Global Supply Chains with IT-innovation. Berlin: Springer Verlag, 2010, pp. 137-156.

[28] S. Henningsson, U. Gal, N. Bjørn-Andersen, and Y. H. Tan, A design proposition for the information infrastructure of international trade, presented in 18th European Conference on Information Systems, Pretoria, South Africa, June 8, 2010.

[29] S. Henningsson and J. Hedman, Information integration in industries: the lack of management and disjoint economic responsibility, International Journal of Information Systems and Supply Chain Management, vol. 3, no. 1, pp. 1-20, 2010.

[30] S. Henningsson, B. Rukanova, and S. Hrastinski, Resource dependency in socio-technical information systems design research, Communication of the AIS, vol. 27, no. 4, 2010. 
[31] A. R. Hevner, S. T. March, J. Park, and S. Ram, Design science in information systems research, MIS Quarterly, vol. 28, no. 1, pp. 75-105, 2004.

[32] A. Higgins, S. Klein, A. Kipp, and A. Mangan, Drug Living Lab-Supply Chain Security and Control, in Accelerating Global Supply Chains with IT-Innovation, Berlin: Springer Verlag, 2010.

[33] Z. Irani, T. Elliman, and P. Jackson, Electronic transformation of government in the UK: A research agenda, European Journal of Information Systems vol. 16, no. 4, pp. 327-335, 2007.

[34] M. Janssen, S. Chun, and J. R. Gil-Garcia, Building the next generation of digital government infrastructures, Government Information Quarterly, vol. 26, no. 2, pp. 233-237, 2009.

[35] M. Janssen and A. Joha, Connecting cloud infrastructures with shared services, in Proceedings of the 11th Annual International Digital Government Research Conference on Public Administration Online: Challenges and Opportunities Puebla, Mexico: Digital Government Society of North America, 2010, pp. 225-226.

[36] A. Kipp, M. Raus, J. Liu, and S. Klein, Value Assessment of Business-to-Government, in Accelerating Global Supply Chains with IT-Innovation. Berlin: Springer, 2010.

[37] S. Klein and A. Higgins, The concept of Living Labs, in Accelarating Global Supply Chains with IT-innovation: ITAIDE Methods and Tools. Berlin: Springer, 2010.

[38] S. Klein, A. Higgins, and B. Rukanova, Network Collaboration Models, in Accelerating Global Supply Chains with IT-Innovation. Berlin: Springer, 2010.

[39] H. Krcmar, N. Bjorn-Andersen, and R. O'Callaghan, Eds., EDI in Europe. Chichester: John Wiley \& Sons Ltd, 1995.

[40] J. Liu, W. Hoffman, and Y. H. Tan, Procedure Redesign Methods, in Accelerating Global Supply Chains with ITInnovation, Berlin: Springer Verlag, 2010.

[41] S. T. March and G. Smith, Design and natural science research on information technology, Decision Support Systems, vol. 15, no. 4, pp. 251-266, 1995.

[42] E. Monteiro and O. Hanseth, Social shaping of information infrastructure: on being specific about the technology, in Information Technology and Changes in Organisational Work. Eds.: Chapman \& Hall, 1996, pp. 325-343.

[43] OECD, E-government for better government, OECD, Paris, 2005

[44] K. Riemer and S. Klein, Network Management Framework: A Life-cycle Perspective, in Managing Dynamic Networks, S. Klein and A. Poulymenakou, Eds. Heidelberg: Springer, 2006, pp. 17-66.

[45] B. Rukanova, Z. Baida, J. Liu, E. Van Stijn, Y. H. Tan, H. Wout, R. T. Wigand, and F. Van Ipenburg, Beer Living Lab-Intelligent Data Sharing, in Accelerating Global Supply Chains with IT-Innovation. Berlin: Springer Verlag, pp. 3-29, 2010.

[46] B. Rukanova, N. Bjorn-Andersen, F. van Ipenburg, S. Klein, G. Smit, and Y. H. Tan, Introduction, in Accelerating Global Supply Chains with IT-Innovation, Berlin: Springer Verlaf, 2010, pp. 3-29.

[47] B. Rukanova, E. Van Stijn, H. Zinner Henriksen, Z. Baida, and Y. H. Tan, Understanding the Influence of Multiple Levels of Government on the Development of Inter-organizational Systems, European Journal of Information Systems, vol. 18, no. 5, pp. 387-408, 2009.

[48] D. Sarantis, Y. Charalabidis, and J. Psarras, Towards Standardising Interoperability Levels for Information Systems of Public Administrations, The Electronic Journal for E-commerce Tools \& Applications (eJETA) Special Issue on Interoperability for Enterprises and Administrations Worldwide, vol. 2, May 2008.

[49] A. M. Sourouni, F. Lampathaki, S. Mouzakitis, Y. Charalabidis, and D. Askounis, Paving the way to eGovernment transformation: interoperability registry infrastructure development, Electronic Government, pp. 340-351, 2008.

[50] S. L. Star and K. Ruhleder, Steps Toward an Ecology of Infrastructure: Design and Access for Large Information Space, Information Systems Research, vol. 7, no. 1, pp. 111-134, 1996.

[51] Y. H. Tan, S. Klein, B. Rukanova, A. Higgins, and Z. Baida, e-Customs Innovation and Transformation: A Research Approach, presented in Bled eCommerce Conference, Slovenia, 2006.

[52] TAXAUD, Electronic Customs Multi-Annual Strategic Plan - TAXUD/477/2004 - Rev. 8 - EN, European Commission, Brussels, Belgium, 2008.

[53] TAXUD, The AEO Compact Model, European Commission/TAXUD, Brussels, 2006.

[54] Tullverket. (10 May 2010). The Stairway. [Online]. Available: http://www.tullverket.se/en/startpage/aboutswedishcustoms/thestairway.4.16ca6de0120cf835feb80001150.html

[55] S. Ulankiewicz, S. Henningsson, N. Bjorn-Andersen, and B. Fluegge, Interoperability Tools, in Accelerating Global Supply Chains with IT-Innovation. Berlin: Springer, 2010.

[56] J. G. Walls, G. R. Widemeyer, and O. A. El Sawy, Building an information systems design theory for vigilant EIS, Information Systems Research, vol. 3, no. 1, pp. 36-59, 1992.

[57] J. E. van Aken, Valid knowledge for the professional design of large and complex design processes, Design Studies, vol. 26, no. 4, pp. 379-404, 2005.

[58] P. Weill and M. Broadbent, Leveraging the new infrastructure Boston: Harvard Business School Press, 1998. 